\title{
Ets2 anchors the prometastatic function of mutant p53 in osteosarcoma
}

\author{
Daniel D. Liu and Yibin Kang \\ Department of Molecular Biology, Princeton University, Princeton, New Jersey 08544, USA
}

\begin{abstract}
Mutations in the tumor suppressor p53 occur in a majority of human cancers. Some gain-of-function (GOF) p53 mutations endow tumor cells with increased metastatic ability, although our understanding of the underlying mechanism remains incomplete. In this issue of Genes \& Development, Pourebrahim and colleagues (pp. 18471857) develop a new mouse model of osteosarcoma in which a GOF mutant p53 allele is expressed specifically in osteoblasts, while the tumor microenvironment remains wild type for p53, allowing for the study of cell-autonomous functions. In this model, the role of GOF mutant $\mathrm{p} 53$ in promoting lung metastasis is shown to be critically dependent on the transcription factor Ets2 and is accompanied by the elevated expression of a cluster of small nucleolar RNAs (snoRNAs).
\end{abstract}

As an archetypal tumor suppressor, p53 is well known for its diverse functions in protecting the genome and maintaining tissue integrity. In response to genotoxic stresses and various other insults, p53 exerts a tumor-suppressive function by triggering cell cycle arrest, apoptosis, senescence, and many other "noncanonical" pathways (Kastenhuber and Lowe 2017). A large majority of p53 mutations occurs in its DNA-binding domain, resulting in loss of its transcriptional activities that are required for tumor suppression. Intriguingly, careful analysis of p53 mutations in genetically modified mouse models and human patient populations also revealed gain-of-function (GOF) activities for some mutant forms of p53, including the ability to promote metastasis (for review, see Muller and Vousden 2014). Several mechanisms have been discovered for GOF mutant p53, most involving its ability to aberrantly bind and modulate the activity of other proteins. For example, mutant p53 can bind to and disrupt the function of other p53 family proteins, including TAp63 and p73, thereby promoting proliferation and metastasis by affecting the expression of downstream genes (Lang et al. 2004; Weissmueller et al. 2014). Mutant p53 has also been reported to interact with Ets2 to promote chemoresistance and alter the expresssion of chromatin regulatory genes

[Keywords: p53; osteosarcoma; snoRNA; metastasis; Ets2]

Corresponding author: ykang@princeton.edu

Article is online at http://www.genesdev.org/cgi/doi/10.1101/gad.307439. 117. to drive cancer progression (Do et al. 2012; Zhu et al. 2015). However, previous mouse models used to study the prometastatic function of GOF mutant p53 often express the mutant allele at the whole-organism level and thus are unable to disentangle cell-autonomous effects from microenvironmental ones. This is a particularly salient concern, as p53 is known to exert non-cell-autonomous effects via stromal cells (Lujambio et al. 2013).

To overcome this limitation, Pourebrahim et al. (2017) developed a new mouse model of osteosarcoma that expresses the GOF mutant p53 ${ }^{\mathrm{R} 172 \mathrm{H}}$ specifically in osteoblasts using lineage-specific Cre, while all other cells remain wild type for $\mathrm{p} 53$. Tumor cells are also genetically labeled with Cre-induced GFP, allowing sensitive tracing of metastatic nodules in secondary organs. Since the vast majority of p53 mutations is somatic, this model better mimics sporadic osteosarcomas in humans and precludes confounding effects from the microenvironment, permitting study of the tumor-intrinsic roles of mutant p53. Interestingly, while $\mathrm{p} 53^{\mathrm{R} 172 \mathrm{H} / \text { null }}$ mice formed primary tumors at slightly slower rates compared with p53 homozygous knockout mice, significantly more lung metastases were developed in p53 mutant mice. This finding is consistent with previous reports on the metastasis-promoting effect of $\mathrm{p} 53^{\mathrm{R} 172 \mathrm{H}}$ in other cancer types using whole-organism knock-in mouse models (for review, see Muller and Vousden 2014).

To understand the molecular basis for the metastasispromoting function of mutant $\mathrm{p} 53$, the investigators performed a series of integrative genomic analyses on primary and metastatic tumor samples derived from mutant p53 versus $\mathrm{p} 53^{\text {null }}$ mice. Transcriptomic profiling analysis revealed a striking difference: A cluster of 24 small nucleolar RNAs (snoRNAs) was expressed at high levels in mutant p53 tumors, while they were barely detectable in p5 $3^{\text {null }}$ tumors. To discover the missing link between mutant p53 and global up-regulation of snoRNAs, the investigators searched for common regulatory motifs among the snoRNA loci. The top candidate that emerged was the transcription factor Ets2, which has notably been

(C) 2017 Liu and Kang This article is distributed exclusively by Cold Spring Harbor Laboratory Press for the first six months after the full-issue publication date (see http://genesdev.cshlp.org/site/misc/terms.xhtml). After six months, it is available under a Creative Commons License (Attribution-NonCommercial 4.0 International), as described at http:// creativecommons.org/licenses/by-nc/4.0/. 
shown to bind to mutant p53 (Do et al. 2012; Zhu et al. 2015). Importantly, genetic deletion of Ets2 in the mouse model completely eliminated the prometastatic effects of mutant p53 without affecting primary tumor growth. Furthermore, Ets2 knockout suppressed expression of all of the mutant p53-induced snoRNAs as well as nearly half of the 179 genes up-regulated in mutant p53 tumors compared with $\mathrm{p} 53^{\text {null }}$ tumors. These results strongly implicate Ets2 as the primary effector of mutant p53's prometastatic function in osteosarcoma (Fig. 1). The unequivocal genetic proof that Ets2 plays a key role in mediating the prometastatic function of mutant p53 indicates potential avenues for developing novel anti-metastasis therapeutic agents, such as inhibitors that block the interaction between Ets2 and mutant p53.

The present study leaves us with some tantalizing questions. For example, do Ets2-regulated snoRNAs play a functional role in mediating the prometastatic function of mutant $\mathrm{p} 53$ ? If so, is there a single snoRNA responsible for most of the phenotype, or does some subset of them play a combinatorial role? Furthermore, are the mutant p53-Ets2-snoRNA axis and their putative functions unique to osteosarcoma or universal in other cancer types? snoRNAs were traditionally thought of as guide RNAs facilitating the post-transcriptional modification of ribosomal RNAs but are now known to regulate a host of other cellular processes, including alternative splicing, chromatin modification, and apoptosis (Mannoor et al. 2012). All of these functions can potentially affect cell-intrinsic properties to promote metastasis. More recently, snoRNAs were reported to serve as important functional cargos in secreted microvesicles or exosomes, which promote the formation of the premetastatic niche in the lungs

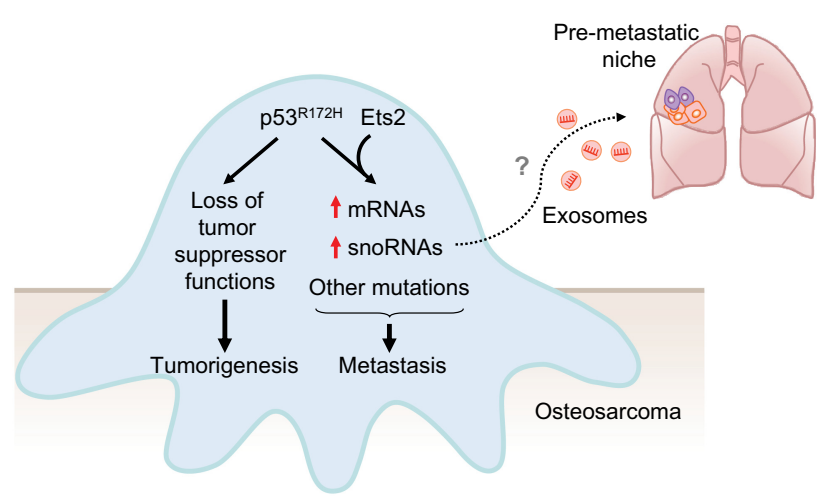

Figure 1. Ets2 mediates the prometastatic function of GOF mutant p53. In osteoblasts, $\mathrm{p} 53^{\mathrm{R} 172 \mathrm{H}}$ mutation leads to the formation of osteosarcoma with increased lung metastasis ability compared with $\mathrm{p} 53^{\text {null }}$ tumors. The prometastatic function of mutant $\mathrm{p} 53$ is mediated largely through its interaction with transcription factor Ets2, which increases the expression level of a number of mRNAs and a cluster of 24 snoRNAs. Although not functionally tested in the present model, exosomal snoRNAs are known to promote metastasis by inducing the formation of the premetastatic niche and may also influence cancer progression through other cell-intrinsic mechanisms, such as regulation of alternative splicing and chromatin modification.
(Liu et al. 2016). Briefly, Liu et al. (2016) found that tumor cells secrete exosomes enriched with snoRNAs, which activate Toll-like receptors in the lung epithelium. Once activated, the epithelial cells secrete chemokines that recruit neutrophils, which infiltrate and prime the site for metastasis initiation. It is plausible that a similar pathway is at play in the present osteosarcoma model. However, further studies are needed to analyze the snoRNA contents in exosomes isolated from p53 mutant tumors in mouse models and human patients as well as their functional impact on the local and distant tumor microenvironment. It is also worth noting that Ets2 is essential for nearly half of the overexpressed mRNAs associated with mutant p53. Furthermore, a number of nonsynonymous mutations were found to be specifically associated with mutant p53 metastatic tumors (Pourebrahim et al. 2017). It is likely that some of these additional Ets2-driven genes and mutant p53-associated secondary mutations also contribute to the metastatic phenotype in a collective way (Fig. 1). Despite these open questions, the study by Pourebrahim et al. (2017) provides an elegant mouse model to study the tumor-intrinsic role of mutant p53, whose prometastatic function is critically dependent on Ets2, with possible involvement of snoRNAs.

\section{References}

Do PM, Varanasi L, Fan S, Li C, Kubacka I, Newman V, Chauhan K, Daniels SR, Boccetta M, Garrett MR, et al. 2012. Mutant p53 cooperates with ETS2 to promote etoposide resistance. Genes Dev 26: 830-845.

Kastenhuber ER, Lowe SW. 2017. Putting p53 in context. Cell 170: 1062-1078.

Lang GA, Iwakuma T, Suh YA, Liu G, Rao VA, Parant JM, Valentin-Vega YA, Terzian T, Caldwell LC, Strong LC, et al. 2004. Gain of function of a p53 hot spot mutation in a mouse model of Li-Fraumeni syndrome. Cell 119: 861-872.

Liu Y, Gu Y, Han Y, Zhang Q, Jiang Z, Zhang X, Huang B, Xu X, Zheng J, Cao X. 2016. Tumor exosomal RNAs promote lung pre-metastatic niche formation by activating alveolar epithelial TLR3 to recruit neutrophils. Cancer Cell 30: 243-256.

Lujambio A, Akkari L, Simon J, Grace D, Tschaharganeh DF, Bolden JE, Zhao Z, Thapar V, Joyce JA, Krizhanovsky V, et al. 2013. Noncell-autonomous tumor suppression by p53. Cell 153: 449-460.

Mannoor K, Liao J, Jiang F. 2012. Small nucleolar RNAs in cancer. Biochim Biophys Acta 1826: 121-128.

Muller PA, Vousden KH. 2014. Mutant p53 in cancer: new functions and therapeutic opportunities. Cancer Cell 25: 304-317.

Pourebrahim R, Zhang Y, Liu B, Gao R, Xiong S, Lin PP, McArthur MJ, Ostrowski MC, Lozano G. 2017. Integrative genome analysis of somatic p53 mutant osteosarcomas identifies Ets2dependent regulation of small nucleolar RNAs by mutant p53 protein. Genes Dev (this issue). doi: 10.1101/gad.304972.117.

Weissmueller S, Manchado E, Saborowski M, Morris JP, Wagenblast E, Davis CA, Moon SH, Pfister NT, Tschaharganeh DF, Kitzing T, et al. 2014. Mutant p53 drives pancreatic cancer metastasis through cell-autonomous PDGF receptor beta signaling. Cell 157: 382-394.

Zhu J, Sammons MA, Donahue G, Dou Z, Vedadi M, Getlik M, Barsyte-Lovejoy D, Al-awar R, Katona BW, Shilatifard A, et al. 2015. Gain-of-function p53 mutants co-opt chromatin pathways to drive cancer growth. Nature 525: 206-211. 


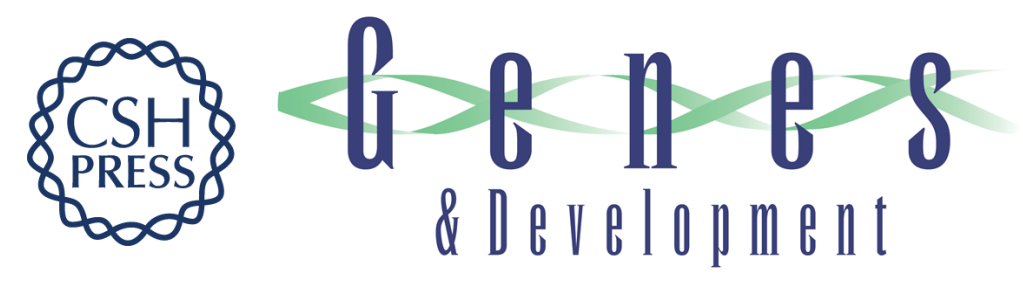

\section{Ets2 anchors the prometastatic function of mutant p53 in osteosarcoma}

Daniel D. Liu and Yibin Kang

Genes Dev. 2017, 31:

Access the most recent version at doi:10.1101/gad.307439.117

\section{Related Content Integrative genome analysis of somatic p53 mutant osteosarcomas identifies Ets2-dependent regulation of small nucleolar RNAs by mutant p53 protein Rasoul Pourebrahim, Yun Zhang, Bin Liu, et al. Genes Dev. September , 2017 31: 1847-1857}

References This article cites 10 articles, 2 of which can be accessed free at: http://genesdev.cshlp.org/content/31/18/1823.full.html\#ref-list-1

Articles cited in:

http://genesdev.cshlp.org/content/31/18/1823.full.html\#related-urls

Creative This article is distributed exclusively by Cold Spring Harbor Laboratory Press for the first Commons License six months after the full-issue publication date (see http://genesdev.cshlp.org/site/misc/terms.xhtml). After six months, it is available under a Creative Commons License (Attribution-NonCommercial 4.0 International), as described at http://creativecommons.org/licenses/by-nc/4.0/.

Email Alerting Receive free email alerts when new articles cite this article - sign up in the box at the top Service right corner of the article or click here.

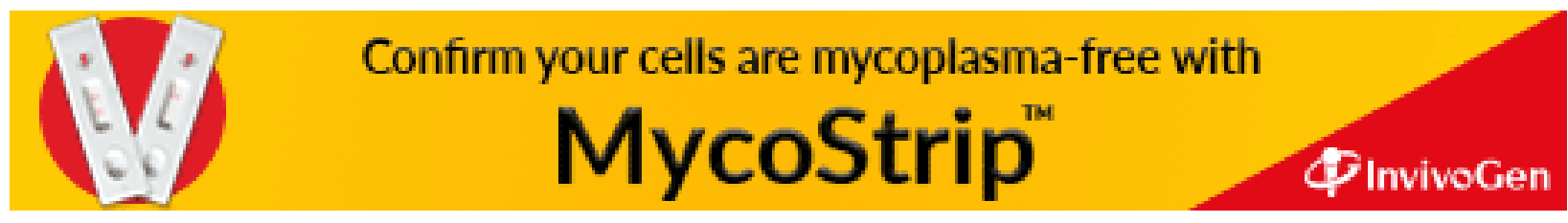

